University of Wollongong

Research Online

Faculty of Informatics - Papers (Archive)

Faculty of Engineering and Information

Sciences

June 2003

\title{
An activity theory framework for computer interface design
}

E. Gould

University of Wollongong, egould@uow.edu.au

I. Verenikina

University of Wollongong, irina@uow.edu.au

Follow this and additional works at: https://ro.uow.edu.au/infopapers

Part of the Physical Sciences and Mathematics Commons

\section{Recommended Citation}

Gould, E. and Verenikina, I.: An activity theory framework for computer interface design 2003.

https://ro.uow.edu.au/infopapers/201

Research Online is the open access institutional repository for the University of Wollongong. For further information contact the UOW Library: research-pubs@uow.edu.au 


\title{
An activity theory framework for computer interface design
}

\begin{abstract}
Computer interface design has the primary purpose of assisting information technology users in their professional activities. In order to accomplish this, users need to be able to work 'through the interface' to complete the tasks which achieve the goals associated with an activity. Although this is the conceptual province of psychology, very little use has been made of psychology in practical interface design. The attempts that have been made appear to have suffered from a lack of connection to real life problems which has been attributed to their foundations in the information processing structure of cognitive psychology. We elaborate an approach to interface design based on the Russian developed activity theory which provides a more complete analysis of human nature and which avoids the problems inherent in the view of humans as exclusively information processors. The relationship of this theory to human computer interaction is considered and its relationship to interface design with activity theory providing a paradigm for the description and understanding of the way humans interact with computers within the context of their environment. A practical example of how this research arose from a problem encountered in an application to a military history interface design will also be discussed.

\section{Disciplines}

Physical Sciences and Mathematics

\section{Publication Details}

This article was originally published as: Gould, E \& Verenikina, I, An activity theory framework for computer interface design, Proceedings of the 25th International Conference on Information Technology Interfaces (ITI 2003), 16-19 June 2003, 301-307. Copyright IEEE 2003.
\end{abstract}




\title{
An Activity Theory Framework for Computer Interface Design
}

\author{
Edward Gould \\ Department of Information Systems \\ University of Wollongong \\ Wollongong, NSW 2522 \\ Australia \\ Phone: +61-242-213755 \\ Fax: $+61-242-214474$ \\ email: e gould anow.edu.au
}

and

Irina Verenikina

Department of Education

University of Wollongong

Wollongong, NSW 2522

Australia

(Formerly Russian Academy of Sciences)

email: irina(a)uow.edu.au

\begin{abstract}
Computer interface design has the primary purpose of assisting information technology users in their professional activities. In order to accomplish this, users need to be able to work 'through the interface' to complete the tasks which achieve the goals associated with an activity. Although this is the conceptual province of psychology very little use has been made of psychology in practical interface design. The attempts that have been made appear to have suffered from a lack of connection to real life problems which has been attributed to their foundations in the information processing structure of cognitive psychology. This paper elaborates an approach to interface design based on the Russian developed Activity Theory which provides a more complete analysis of human nature and which avoids the problems inherent in the view of humans as exclusively information processors. The relationship of this theory to human computer interaction is considered and its relationship to interface design with Activity Theory providing a paradigm for the description and understanding of the way humans interact with computers within the context of their
\end{abstract}

environment. A practical example of how this research arose from a problem encountered in an application to a military history interface design will also be discussed.

Keywords. Activity Theory, Interface, Web page, checklist, scenario

\section{Introduction}

Studying the way people use computer technology in order to build more usable systems is not new. The human-computer interaction ( $\mathrm{HCl}$ ) movement has been active since the early 1980's, driven mainly by psychologists in North America and Europe and based on an approach dominated by cognitive science. Many researchers in $\mathrm{HCl}$ now realise the shortcomings of the cognitive science approach to understanding human cognition in its relationship to the human use of computer technology. This is due in some part to the failure of cognitive science to distinguish between the way information is processed in 
humans and the way it is processed in computers. The cognitive approach sees the computer as a replacement for the human in intellectual spheres with the implication that a computer program is equivalent to the process of human thinking. To understand why this has come about we will look briefly at cognitive psychology then contrast it with the Vygotskian approach which emphasises tool mediation and the importance of work activity as a unit of analysis and the contextuality of computer use.

\section{Cognitive Psychology}

\subsection{Background}

Cognitive processes have been studied in a number of fields; namely neuroscience and psychology as well as the areas of cybernetics and artificial intelligence. "Cognition is the activity of knowing: the acquisition, organisation, and use of knowledge. It is something that organisms do and in particular something that people do. For this reason the study of cognition is the study of psychology, and theories of cognition are psychological theories" [13].

The study of mental processes or cognitive psychology has gained in significance since the 1960's. It looks at such topics as perception, memory, attention, pattern recognition, problem solving, language, cognitive development and many others. Neisser [13] claims that this renewed interest in subjects that had lain dormant for many years was the advent of the computer age. With the computer's ability to accept data, manipulate symbols and store items in memory for recall, cognicists were reassured that the processes they were studying were real and capable of being modelled.

This in turn led to the development of a branch of psychology known as cognitive science. Donald Norman [15] defines cognitive science as the search for understanding of cognition, be it real or abstract, human or machine.' He goes on to say that a major component of cognitive science is the specification of the rules and mechanism by which cognitive systems operate. It admits the importance of physical symbol processing but allows variety in the choice and the specification of cognitive functions. This means that the study of the specialised mechanisms of cognitive functioning, the rules of language, the relevant biological principles as well as symbol processing are all fundamental to cognitive science.

\subsection{The Information Processing Model}

Computer science has had a significant theoretical effect on the formation of this model. This has had a positive aspect in that it has led to a good understanding via common terminology between systems developers and cognitive psychologists. But, it also has had a negative effect in that its conceptual roots in information processing have stultified its assimilation of new ideas [8].

An information processing model (Figure 1) is based on the assumption that cognition can be represented as a series of hypothetical stages during which operations are performed on incoming information or stimuli. These stimuli such as light, sound, odours and so on are transformed to meaningful symbols in our brains referred to as 'internal representations'. The last component of the model is the output or reaction of the person to the input stimulus.

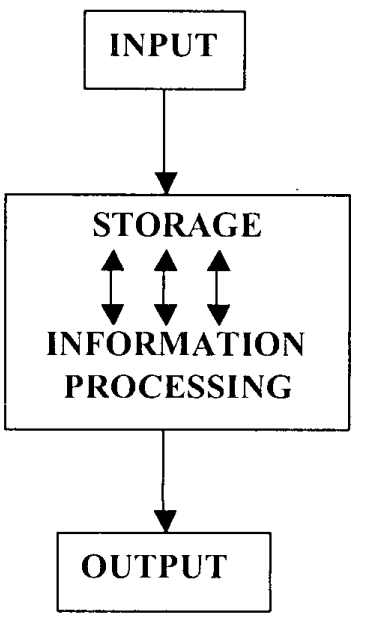

Figure 1. Human Information Processing

\subsection{The Beginnings of Dissent}

In 1976 Neisser [13] was critical of the way in which this branch of psychology was developing as a study of the mind as an information processing device. He said then that 'cognitive psychologists must make a greater effort to understand cognition as it occurs in the ordinary environment and in the context of natural purposeful activity ... and pay more attention to the details of the real world in which 
perceivers and thinkers live.' He saw perception and cognition as not just operations performed in the head but as transactions with the world.

Donald Norman [14] explains the position thus: 'after an initial flurry of activity (into symbolic cognition), progress slowed. The problem of understanding human cognition still loomed large'. He puts this down to factors such as the enormous amount of knowledge required to deal with a very complex world and the impossibility of observing all the relevant aspects of human cognition. This has led to a modification to cognitive science, that even though our view of the world is related to the stimulation received through the senses, it is modified in a way that is related to past experiences and present situations.

The next section details a psychological philosophy which analyses human beings in their natural environment taking into account cultural factors and developmental aspects of human mental life. When the framework of Activity Theory is used as a basis for HCI it sheds a new light on the underlying principles of human activity.

\section{Activity Theory}

\subsection{Vygotskian Psychology and IT}

Within the HCI community 'Activity Theory' is better known as a term for Vygotskian psychology no doubt due to the work of Yjro Engstrom (e.g. [7]). The original foundations for Activity Theory were laid down by Vygotsky in the period from 1924 until his death in 1934. His basic idea was that human activity is mediated by cultural signs: words and tools, which causes changes in a person's activity, and thus its mental reflection. The structure of external and internal activity thus constituting a unity. Activities are 'initially carried out on the external plane, and are then internalised with many psychological functions such as attention, memory, and thinking [18]. Vygotsky's work was continued by A.N. Leontiev who developed a conceptual framework for the theory of Activity based on mental reflection and the corresponding activities evident in the evolution of animals and humans. We now look at how Activity Theory can be used as a framework for the development of the interaction between humans and computers.

\subsection{Work Activity}

As indicated previously, the limitation of modelling methods to support the design process may be due to their omission of 'context'. However, the notion of context needs to be conceptualised. Kuutti [10] points to the importance of focusing on work activities as the context of Information Systems (IS) saying, 'We are never developing only information systems, but the whole of the work activity where it will be utilised'. But how do we conceptualise work activities?

Leontiev [12] has developed the inner structure of activity based on the principle of analysis by units, meaning that all main properties are inherent in the whole. The units of activity are actions and operations organised in a hierarchical structure. Activities are distinguished on the basis of their motive; actions, on the basis of their goals; and operations on the basis of the conditions under which actions are carried out (Figure 2). The conceptualisation of these 'units' makes it is possible to identify: (a) the reason for an activity by defining its motive; (b) the aim of an activity by defining the goal toward which the subject strives and (c) the means by which an activity is carried out by defining the conditions under which the action takes place.

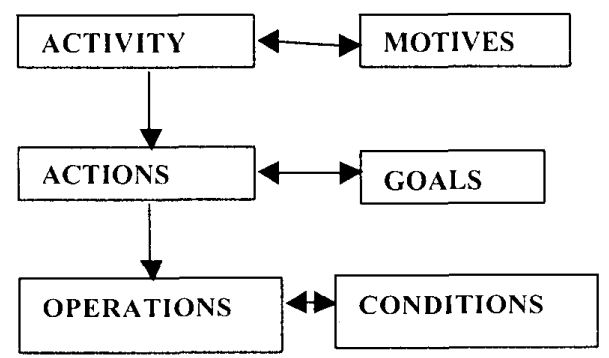

Figure 2. Activity Theory Hierarchy

Technology-in-use changes work conditions by increasing the level of automation. From a psychological point of view automation is understood to be the 'technisation' of human operations. But although operations may be carried out by a machine (e.g. 'technisation' of mental processes), they still realise the action and its goal of the subject. Action and operations do not constitute any kind of 'separateness' in relation to the activity [12]. Consequently, the view of computer applications as 'replacements' for operations (e.g. senso-motoric level of 
analysis) is not sufficient for analysing work situations. The tool is not simply added on to human activity, rather it transforms it [17]. Analysis of any kind of 'work behaviour' must therefore include all three levels of analysis: activity, action and operation, the minimal unit of analysis being the activity

\subsection{Context of HCI}

Within $\mathrm{HCl}$ the highest level of contextualisation is usually the task level. Task analysis based on the behaviouristic method identifies the outer behaviour of work activities and is a popular basis for defining the uses to which a computer interface will be put. Although this analysis may have an important function e.g. in order to describe job requirements, the distinction between human and computer tasks such as analysis is rather limited in relation to identifying the psychological processes in work activities. Focusing on the observed behaviour does not say much about the inner structure of activity as the same observed behaviour may correspond to different motives and goals of the individual. For instance operating a computer can be a playing, learning or a working activity thus having a different personal sense for subjects. Landauer's [11] suggestion for studying cognition within its task context, does not solve the problem of contextualisation. Human procedures are not determined by the task, but on special characteristics of the case [5]. In other words, for task analysis to have any real significance in design, it needs to be embedded within the work activity. It $\dot{\mathrm{B}}$ also impossible to make a general classification of activities, actions or operations because activities are in a constant state of development. The identification is dependent on the activity of the individual.

Consequently, the automation of mental processes should not be seen as a replacement for human work, nor as a supplement, but as a reorganisation - "we are confronted with the reorganisation of human activity and the appearance of new forms of mediation in which the computer as a tool of mental activity transforms this very activity". Machines mediate the activity of people and thus require a specific type of activity to operate them [17].

\section{Practical Example}

\subsection{Activity Theory and Web Pages}

The application of Activity Theory principles to the design of a web based information system was the purpose of a grant made to the Activity Theory Usability Laboratory at Wollongong University. The data is non-traditional in nature being historical and relating to participants in World War 1 (WW1). Its purpose is to allow members of the public to trace ancestors who took part in the Great War. The interface uses time dependent maps to enable inquirers to follow the progress of individual participants in the conflict.

Although a massive amount of data is available via the Australian War Memorial (AWM) organisation it is presented in a form that leaves inquirers with a feeling of frustration that further details of the exact locations of where family members were stationed during the conflict is not readily available. The reasons for this are related to the absence of key data and the lack of a suitable interface navigation system. The aim of this project therefore was to address this problem by linking together the available data into a form whereby inquirers could trace the various locations of their relatives as their battalions were moved between the battlefields in France and Belgium. The process involves the provision of map-based links to the movement of the army group throughout the course of the war. Relatives would then be able to trace the whereabouts of a soldier throughout the passage of the conflict until they returned home or were killed.

\subsection{Use of Checklists}

In attempting to move from the theoretical structure of an Activity to its practical application the use of checklists has been suggested [9]. Bodker and Peterson [2] propose that checklists be used to present theory in an operational form thus enabling them to be used as a mediating tool in the investigation and design process. They give examples of four checklists which they have developed each focusing on particular areas of relevance to their study of artefact useability. Kaptelinin and Nardi [9] make a distinction between checklists for design and checklists for evaluation. Their checklists cover the main basic principles of Activity Theory namely the activity hierarchy (fig 2), object orientedness, internalisation/externalisation, mediation and development as outlined in Leontiev [12]. These 
terms have been made more relevant to useability by calling object orientedness "Environment", internalisation/externalisation "Structure and Dynamics of Interaction" and mediation and development simply "Development". We have taken these extensive checklists and formulated a version of the design checklists to suit our needs.

The modified checklists from the Kaptelinin/Nardi original are presented below and are structured into the four Activity Theory areas nominated above. Only two abbreviated lists have been presented because of space restric tions.

\subsubsection{Hierarchical structure of activity}

Understanding the use of any technology should start with identifying the goals of target actions, which are relatively explicit, and then extending the scope of analysis both "up" (to higher-level actions and activities) and "down" (to lower level actions and operations).

People who will use new technology

- Wide cross section of community

Goals of target actions

- Time/geographical/conflict-based goals

Parties involved in the process of design

- AT research group/AWM researchers

Goals of designing a new system

- Make available individual soldier location throughout $W W I$

Criteria of success/ failure of design

- The system should provide an easy and interconnected access to individual cases

\subsubsection{Environment (object-orientedness)}

Human beings live in a social, cultural world. They achieve their motives and goals by active transformation of objects in their environments. This section of the checklist identifies the objects involved in target activities and constitutes the environment of the use of the target technology

Resources available to the parties involved in the design of the system

- Faculty grant/research students

Rules, norms, and procedures regulating interaction between the parties

- Three teams (collection, database, web system) reporting to supervisor

Role of existing technology

- Extensive use of the internet
Access to tools and materials

- General availability of internet possible use of $C D$

\subsubsection{Structure and Dynamics of Interaction}

Activities include both internal (mental) and external components which can transform into each other. Computer systems should support both internalisation of new ways of action and articulation of mental processes, when necessary, to facilitate problem solving and social coordination (list suppressed).

\subsubsection{Development}

Activities undergo permanent developmental transformations. Analysis of the history of target activities can help to reveal the main factors influencing the development. Analysis of potential changes in the environment can help to anticipate their effect on the structure of target activities (list suppressed).

\section{Use of Scenarios}

A scenario can be defined as a description of what a user has to do and the method by which specific tasks would be performed. They have the specific advantage of being concrete and specific to the domain and problem at hand thus allowing software developers to investigate various design options. More specifically scenarios force the designer to document the psychological design rationale thus becoming more aware of the natural evolution of user tasks and the artefact, taking advantage of how consequences of one design can be used to improve later designs [4]. The use of goal based scenarios has been described by Schank [16] and applied educational software development by Dobson \& Reisbeck [6], to design by Carroll [3] and to informatics research by Bergqvist et al [1]. In this project scenarios were used by the design team in a role playing situation, where the predicted actions of the users were played out and possible solutions to their behaviour recorded. This process was driven by the goals identified in the Activity Theory hierarchy and took the form of "what if" sessions.

Based on this investigation it was clear that use of the final system would be via three main scenarios. Entry to the system would be via two of what we called pre-scenarios. The prescenarios were the ways by which inquirers 
found enough information to enter the main system and are part of the whole 'action life cycle' from goal setting to the final outcome. Given that one main goal is to trace family members the first pre-scenario is to use the Australian War Memorial (AWM) databases to trace the battalion to which the family member belonged and use this as an input to our system. Alternatively if the family member was killed in action or subsequently died of wounds then the date of death or injury would be the entry point to our system. Both pre-scenarios are possible through existing AWM systems. Once our system was accessed the three main scenarios are facilitated. One was date/time based (uses prescenario two) and involved the inquirer entering the system with the goal of finding the location of a war participant on a particular date. Another related to the goal of tracing the battalion's progress (pre-scenario one) during the passage of the conflict through geographical locations and the third involved an inquirer searching for particular conflicts. It was assumed that preinformation for this scenario would be from sources outside either our system or AWM web based archives but most likely via military histories. The scenario of school children accessing our system in response to projects set by teachers on particular battles gave rise to this scenario. Other scenarios were considered but all were reducible to one of these three which were referred to as time, geography and conflict. The database was then designed to facilitate interrogation based on the time/geography/conflict structure and tables set up accordingly.

\section{Summary of the Application of Activity Theory Principles to Web Design}

This research is part of a wider investigation into the use of Vygotskian tool mediation as a basis for interface design. The aim of this preliminary prototype project is to identify and apply specific activities to the use of web based information systems. Although there are many details to be "fleshed" out the activity theory checklist approach has been shown to be a feasible tool in the design of this particular web based information system. The checklists as they stand are barely adequate to provide enough detailed guidance for designers and work is underway in addressing this. Technical problems relating to size of the ipg files containing the maps have hampered the development to some extent and work on speeding up their recovery is still being undertaken.

\section{Conclusion}

The example given here illustrates the difficult task of relating Activity Theory to a set of tools which are useful in the design of webbased information systems. This paper has looked at checklists, scenarios, tool mediation and Leontiev's hierarchy as a means of achieving some guidance to design. Whereas the disjointed nature of cognitive psychology (described by Leontiev [12] as a study of the nuts and bolts of psychology) has given rise to a number of design tools, the nature of Vygotsky's theory makes this a much more difficult task. The theory is a complete whole in itself and extracting portions of it to aid design runs the risk of developing tools that relate to only one part of the theory. Hence falling into the same trap as the nuts and bolts approach of cognitive psychology.

Further research is continuing in this area and no doubt Vygotsky's valuable theories will eventually find their way into solid design techniques for the many types of computer information systems.

\section{References}

[1] Bergqvist, J, Bjork, S., Borjesson, M \& Ljungstrand, $\mathrm{P}$, Scenarios for Multidisciplinary Design Purposes, Proceedings of the $22^{\text {nd }}$ IRIS Conference, Keuruu, Finland, 1999

[2] Bodker, S and Petersen, M., Usability Work: from Snapshop to Development of Use, Paper presented at ISCRAT'98, Aahus, Denmark, 1998,

[3] Carroll, J.M., Making Use: Scenarios and Scenario-Based Design, OZCHI 2000 Conference Proceedings, December, pp 3648,2000

[4] Dix, A., Finlay, J, Abowd, G., Beale, R., Human-Computer Interaction, Prentice-Hall, 1993

[5] Draper, S, Activity Theory: The New Direction For HCI?, Intl Journal of Man Machine Studies, Vol 24, 1992

[6] Dobson, W. and Reisbeck, C. Tools For Incremental Development of Educational Software Interfaces, Proceedings of CHI'98, Los Angeles, July, 1998 
[7] Engestrom, Y, 1990, Learning, Working and Imagining - Twelve Studies in Activity Theory, Orientakonsultit Oy, Helsinki

[8] Kaptelinin, V, "Human-Computer Interaction in Context: The activity Theory Position", Proceedings East-West Intl.Conference on Human-Computer Interaction, St Petersburg, Russia, 1992

[9] Kaptelinin, V., and Nardi, B, The Activity Theory Checklist: A Tool for Representing the "Space" of Context, Unpublished communications with the authors and tutorial at CHI"97, http:/www.acm.org/sigs/sigchi/chi97/proceed ings/tutorial/bn.ht., 1997

[10]Kuutti, K, Activity Theory as a Potential Framework for Human-Computer Interaction, In Nardi, B., Context and Consciousness; Activity Theory and Human Computer Interaction, MIT Press, Cambridge, Mass., 1995

[11] Landauer, T.K, Lets Get Real: A Position Paper on the Role of Cognitive Psychology in the Design of Humanly Useful and Usable Systems, in Carroll, J.M. (Ed), 1991, Designing Interaction, Psychology at the Human-Computer Interface, Cambridge Universtiy Press, Cambridge, UK., 1991

[12] Leontiev, A.N., Activity, Consciousness and Personality, Prentice-Hall, Englewood Cliffs, NJ, 1978

[13] Neisser, U., Cognition and Reality. Principles and Implications of Cognitive Psychology, W.H.Freeman \& Co., 1976

[14] Norman, D. A, Cognition In The Head And In The World: An Introduction To The Special Issue On Situated Action, Cognitive Science, Vol 17 No I, Jan-Mar, Ablex, NJ., 1993

[15] Norman, D.A, What Is Cognitive Science?, in Norman, D.A., (Ed), Perspectives on Cognitive Science, Ablex, 1981

[16] Schank, R., GoatBased Scenarios: A Radical Look At Education, J of learning Sciences 3,4, July, 1994, pp54-60.

[17] Tikhomirov, O.K., The Psychological Consequences Of Computerisation, in Wertsch, J. V., (Ed) The Concept of Activity in Soviet Psychology, Armonk, NY: Sharpe. 1981 ,

[18] Vygotsky, L.S., The Instrumental Method in Psychology. In Wertsch, J. V., (Ed), 1981, The Concept of Activity in Soviet Psychology, Armonk, NY: Sharpe 1981, 